\title{
Corrigendum
}

\section{Corrigendum to "Dynamic Analysis and Circuit Design of a Novel Hyperchaotic System with Fractional-Order Terms"}

\begin{abstract}
Abir Lassoued (iD) and Olfa Boubaker $(\mathbb{D})$
University of Carthage, National Institute of Applied Sciences and Technology, Centre Urbain Nord, BP 676, 1080 Tunis Cedex, Tunisia

Correspondence should be addressed to Abir Lassoued; lassoued.abir5@gmail.com

Received 10 July 2019; Accepted 11 July 2019; Published 21 July 2019

Copyright (c) 2019 Abir Lassoued and Olfa Boubaker. This is an open access article distributed under the Creative Commons Attribution License, which permits unrestricted use, distribution, and reproduction in any medium, provided the original work is properly cited.
\end{abstract}

In the article titled "Dynamic Analysis and Circuit Design of a Novel Hyperchaotic System with Fractional-Order Terms" [1], there was an error in the authors' affiliation. The corrected affiliation is shown above.

\section{References}

[1] A. Lassoued and O. Boubaker, "Dynamic analysis and circuit design of a novel hyperchaotic system with fractional-order terms," Complexity, vol. 2017, Article ID 3273408, 10 pages, 2017. 


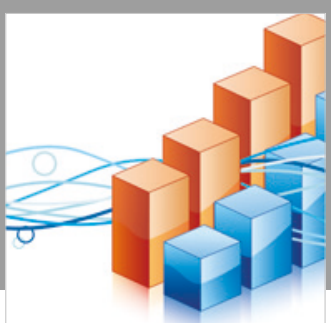

Advances in

Operations Research

\section{-n-m}
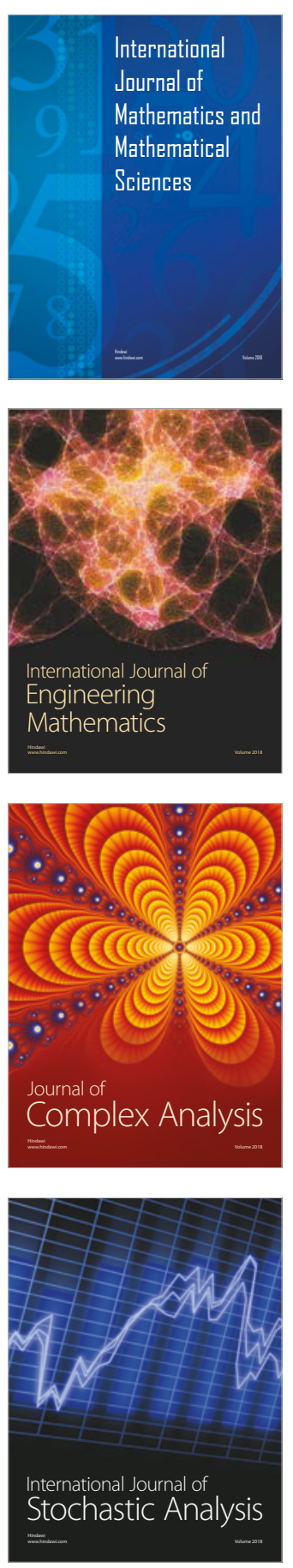
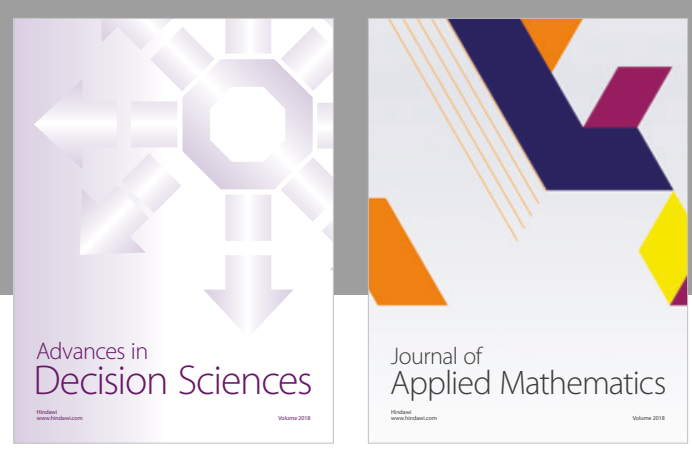

Journal of

Applied Mathematics
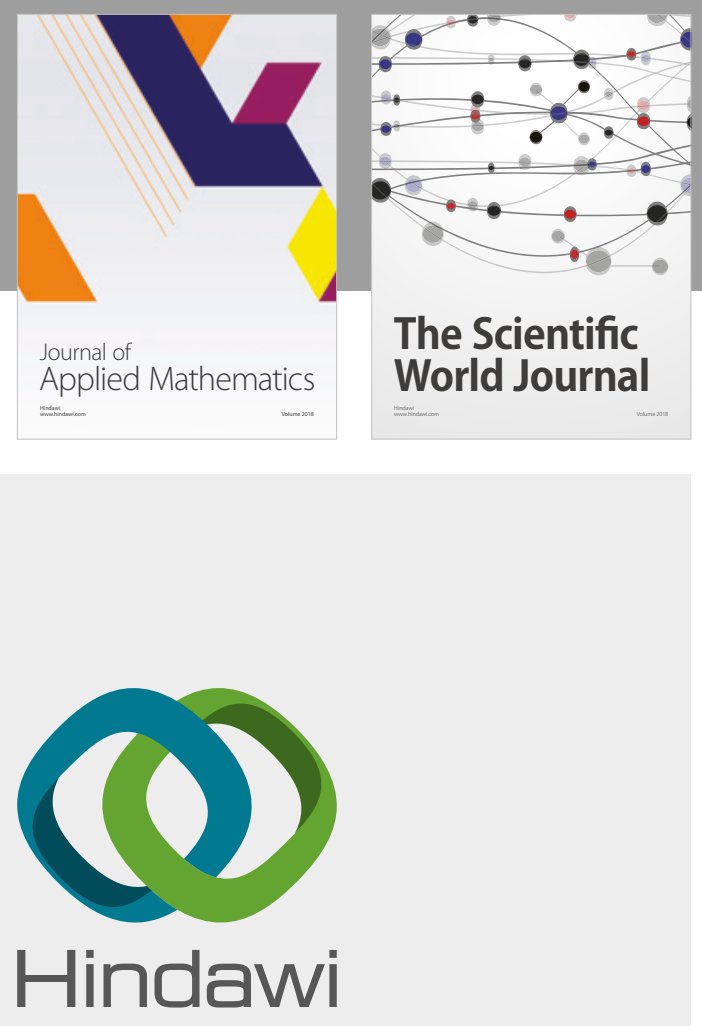

Submit your manuscripts at

www.hindawi.com

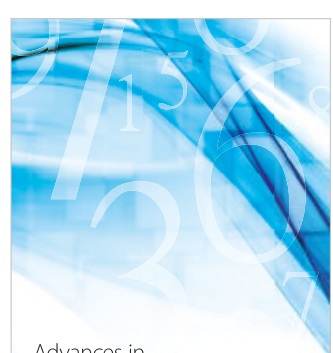

Advances in
Numerical Analysis
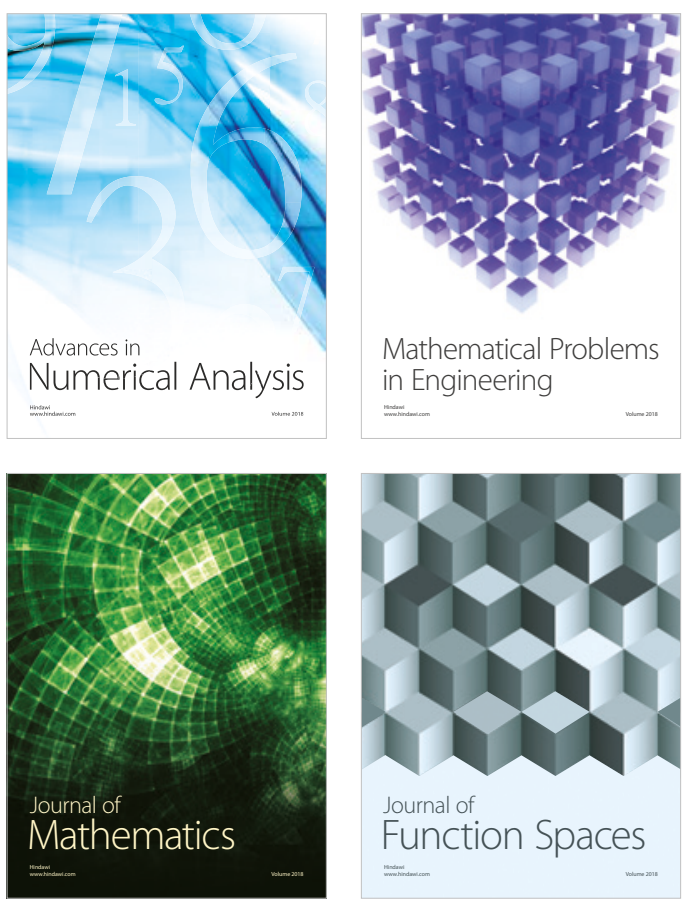

Mathematical Problems in Engineering

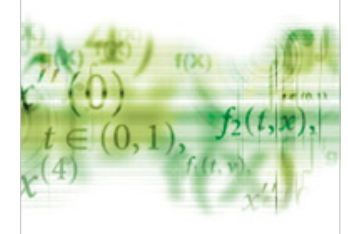

International Journal of

Differential Equations

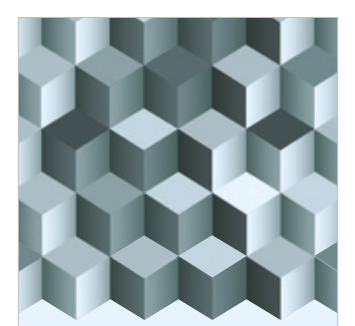

Journal of

Function Spaces
The Scientific

World Journal

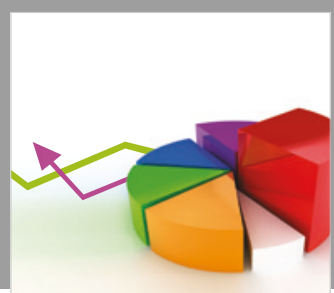

Journal of

Probability and Statistics
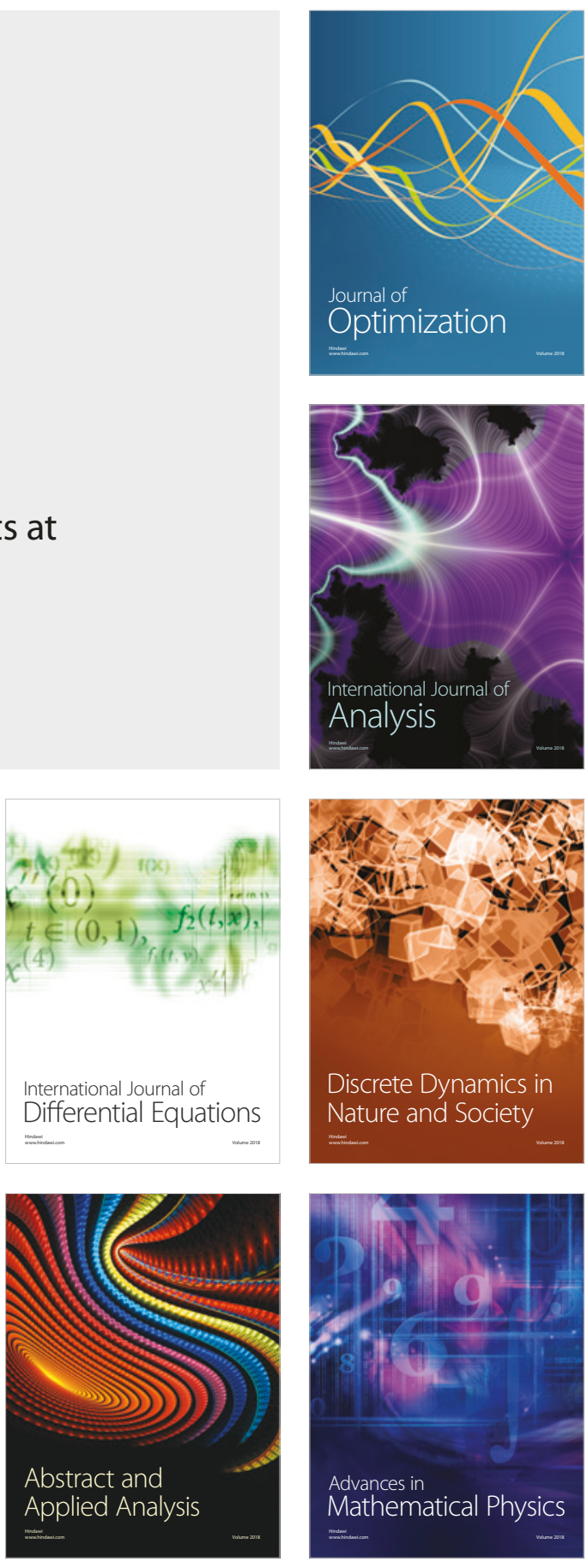